\title{
Antitumor effects and mechanisms of olaparib in combination with carboplatin and BKM120 on human triple-negative breast cancer cells
}

\author{
HUI ZHAO ${ }^{1,2^{*}}$, QIANXI YANG ${ }^{1,2 *}$, YUNHUI $\mathrm{HU}^{1}$ and JIN ZHANG ${ }^{1}$ \\ ${ }^{1}$ The Third Department of Breast Cancer, China Tianjin Breast Cancer Prevention, Treatment and Research Center, \\ Tianjin Medical University Cancer Institute and Hospital, National Clinical Research Center of Cancer, \\ Tianjin 300060; ${ }^{2}$ Department of General Surgery, The Fifth Center Hospital of Tianjin, \\ Tianjin 300450, P.R. China
}

Received March 9, 2018; Accepted September 17, 2018

DOI: 10.3892/or.2018.6716

\begin{abstract}
Triple-negative breast cancer (TNBC) refers to a heterogeneous group of tumors, for which there is currently a lack of targeted therapies. Poly(ADP-ribose) polymerase (PARP) inhibitors, phosphatidylinositol 3-kinase (PI3K) inhibitors and carboplatin (CBP) have demonstrated sufficient efficacy and safety for their use as individual drugs for the treatment of TNBC; however, their effects on TNBC when used as a combination have not been investigated. The primary objectives of the present study were to determine the effects of a combination of CBP, olaparib and NVP-BKM120 (BKM120), and to investigate the mechanism underlying their effects on TNBC cells. The drug combination was cytotoxic to TNBC cells, both with regards to short-term and long-term sensitivity, as determined using colony forming assays, and they exerted strong synergistic effects on MDA-MB-231 and CAL51 cell lines. All drugs affected cell cycle progression, and western blotting and immunofluorescence indicated that the the drug combination exerted its cytotoxicity via DNA damage, enhancing non-homologous end joining repair and inhibiting homologous recombination repair. These data provide a strong rationale to explore the therapeutic use of olaparib in combination with CBP and BKM120 in animal models, and later in clinical trials on patients with TNBC.
\end{abstract}

Correspondence to: Professor Jin Zhang, The Third Department of Breast Cancer, China Tianjin Breast Cancer Prevention, Treatment and Research Center, Tianjin Medical University Cancer Institute and Hospital, National Clinical Research Center of Cancer, Huan-Hu-Xi Road, Ti-Yuan-Bei, Tianjin 300060, P.R. China E-mail: yunhuihu200408@163.com

${ }^{*}$ Contributed equally

Key words: olaparib, PARP inhibitor, PI3K inhibitor, DNA damage, triple-negative breast cancer

\section{Introduction}

Triple-negative breast cancer (TNBC) is a heterogeneous disease group characterized by lack of estrogen receptor (ER), progesterone receptor (PR) and human epidermal growth factor 2 (Her2) expression. Contrary to ER-positive and Her2-positive breast cancers, which are treated with targeted therapies such as tamoxifen and herceptin, the management of TNBC is not standardized and it is based on the use of traditional cytotoxic drugs that induce a plethora of side-effects. In addition, conventional chemotherapy is not always effective for the treatment of these tumors and many patients relapse, normally with fatal consequences. Therefore, there is an urgent requirement for more specific therapies for TNBC (1).

Olaparib is an oral inhibitor of poly(ADP-ribose) polymerase (PARP), which blocks base-excision repair by trapping PARP at the site of DNA damage, thus leading to the collapse of DNA replication forks and the accumulation of DNA double stranded breaks (DSBs) (2). Therefore, PARP inhibition has been identified as a targeted therapy that may exploit intrinsic defects in numerous cancer cells, and has been reported to be selectively cytotoxic in breast cancer harboring germ line mutations in BRCA1, DNA repair-associated (BRCA1) and BRCA2, DNA repair-associated (BRCA2) (3).

The phosphatidylinositol 3-kinase (PI3K) pathway is an important signaling network that regulates essential cellular functions, including cell growth, proliferation and survival (4,5). NVP-BKM120 (BKM120) is a pan-class I PI3K inhibitor currently in Phase I/II clinical trials $(6,7)$, which has been reported to exert antiproliferative, pro-apoptotic and antitumor activity in various cell lines, as well as in xenograft models of cancers with or without aberrant PI3K pathway activation $(8,9)$. The combination of the PI3K inhibitor, BKM120, and the PARP inhibitor olaparib exhibits synergistic therapeutic effects on a genetic mouse model of BRCA1-associated breast cancer, as well as on the treatment of BRCA1-proficient TNBC (10). The results from these studies have prompted clinical investigations into the combined use of inhibitors of PI3K and PARP, and phase I clinical trials are currently enrolling patients with TNBC (11). 
The single agent carboplatin (CBP) has been extensively investigated, and its effects have been analyzed in a trial on patients with TNBC enriched for patients with cancers harboring BRCA mutations (12). CBP crosslinks with purine bases in the DNA, interfering with DNA repair mechanisms, thus leading to DNA damage and the induction of apoptosis. However, DNA damage triggers intrinsic repair mechanisms, which are associated with drug resistance (13). To ensure that cell cycle progression takes places without errors and in an orderly fashion, non-homologous end joining (NHEJ) repair begins in the $\mathrm{G}_{1}$ phase and homologous recombination (HR) begins in the $S / G_{2}$ phase; in addition, the repair of DSBs is strictly regulated by the cell cycle (14). The targeting of DNA repairs with DNA DSB-inducing agents, such as platinum compounds, may be beneficial for the treament of patients with breast cancer that are BRCA1 or BRCA2 mutation carriers (15). Therefore, blocking DNA repair pathways is a logical strategy for the development of therapeutic options.

The present study aimed to explore the effects of a combination of CBP, olaparib and BKM120 on a TNBC cell model. The results detected a strong synergistic effect, providing a strong rationale for the use of this combination in further studies using animal models and future clinical trials on patients with TNBC.

\section{Materials and methods}

Cell lines, culture conditions and reagents. MDA-MB-231 and MCF-7 cells were obtained from the American Type Culture Collection (Manassas, VA, USA). CAL51 cells were obtained from the German Collection of Microorganisms and Cell Cultures (Leibniz Institute DSMZ, Braunschweig, Germany). All cells were maintained in RPMI-1640 medium (Sigma-Aldrich; Merck KGaA, Darmstadt, Germany) supplemented with 10\% fetal bovine serum (Corning Incorporated, Corning, NY, USA) and $1 \%$ penicillin-streptomycin (Corning Incorporated) at $37^{\circ} \mathrm{C}$ in an atmosphere containing $95 \%$ air and $5 \% \mathrm{CO}_{2}$. The triple negative phenotype was validated by immunoblotting (data not shown). Cells were discarded 15 passages after initial culture. The PARP inhibitor olaparib (AstraZeneca, Cambridge, UK) was dissolved in dimethyl sulfoxide (DMSO) at a final concentration of $10 \mathrm{mM}$; BKM120 was purchased from Selleck Chemicals (Houston, TX, USA) and dissolved in DMSO at a final concentration of $1 \mathrm{mM}$; and CBP was purchased from Qilu Pharmaceutical Co., Ltd. (Jinan, China) and dissolved in phosphate-buffered saline (PBS) at a final concentration of $40 \mu \mathrm{M}$. All stock solutions were stored at $-20^{\circ} \mathrm{C}$.

Toxicity assay. Drug toxicity was determined as previously described (16). Briefly, cells were seeded in 96-well plates (3,000 cells/well) in triplicate and were treated with a range of concentrations of the indicated drugs, as depicted in Fig. 1, at $37^{\circ} \mathrm{C}$ for $72 \mathrm{~h}$. Controls were treated with vehicle (either PBS or DMSO). Drug toxicity was assessed after staining with MTT (Beijing Solarbio Science \& Technology Co., Ltd., Beijing, China) by measuring the production of formazan, which is directly proportional to the number of viable cells. Briefly, to each well of a 96-well plate containing $100 \mu 1$ medium, $10 \mu 1$ MTT solution (5 mg/ml MTT in PBS) was added and incubated at $37^{\circ} \mathrm{C}$ for $2 \mathrm{~h}$. Solubilization of formazan was achieved following the addition of $100 \mu \mathrm{l}$ solubilization solution [ $40 \%$ dimethylformadide $\mathrm{v} / \mathrm{v}$ in $2 \%$ glacial acetic acid $\mathrm{v} / \mathrm{v}$, to which $16 \%$ sodium dodecyl sulphate ( $\mathrm{pH} 4.7$ ) had been added $w / v]$ and reading optical density at $570 \mathrm{~nm}$. For drug combination experiments, a combination index (CI) was calculated using CalcuSyn 2.0 software (Biosoft, Cambridge, UK) based on the Chou and Talalay method (17). CI values between 0.1 and 0.9 refer to different grades of synergism, values between 0.9 and 1.1 refer to additive effects, whereas values $>1.1$ refer to antagonistic effects.

Colony forming assay. The capacity of cells to survive and proliferate following drug treatment was determined, according to a previously described method (16). Briefly, cells were seeded in 6 -well plates $\left(1 \times 10^{5}\right.$ cells/well $)$, and were treated with $2.5 \mu \mathrm{M}$ olaparib, $1 \mu \mathrm{M} \mathrm{CBP}$ and/or $1 \mu \mathrm{M}$ BKM120, after 1 day. After 10 days at $37^{\circ} \mathrm{C}$, the surviving proliferating clones were stained with $0.4 \%(\mathrm{w} / \mathrm{v})$ crystal violet for $30 \mathrm{~min}$ at room temperature. The dye was solubilized using $33 \%(\mathrm{v} / \mathrm{v})$ acetic acid and the optical density was determined at $592 \mathrm{~nm}$.

Cell cycle analysis. Flow cytometric analysis was used to evaluate alterations in the cell cycle, as previously described (18). Cells $\left(1 \times 10^{6}\right)$ were fixed in $70 \%$ ethanol overnight at $4^{\circ} \mathrm{C}$, washed twice with PBS, treated with RNase A (Sigma-Aldrich; Merck KGaA; final concentration, $50 \mu \mathrm{g} / \mathrm{ml}$ ) for $15 \mathrm{~min}$ at $4^{\circ} \mathrm{C}$ and stained with propidium iodide (Sigma-Aldrich; Merck KGaA; final concentration, $50 \mu \mathrm{g} / \mathrm{ml}$ ) overnight at $4^{\circ} \mathrm{C}$. Samples were analyzed using a BD FACSCanto II (Becton Dickinson, San Jose, CA, USA) flow cytometer, in order to determine the proportion of cells at each stage of the cell cycle using flow cytometry software (ModFit LT; Verity Software House, Inc., Topsham, ME, USA).

Western blotting. Protein expression was determined as previously described (16). Briefly, cells were harvested and suspended in radioimmunoprecipitation assay lysis buffer (Beijing Solarbio Science \& Technology Co., Ltd.) supplemented with protease and phosphatase inhibitors (1 mM sodium fluoride, $2 \mathrm{mM}$ sodium orthovanadate, $1 \mathrm{mM}$ phenylmethylsulfonyl fluoride), placed on ice for $30 \mathrm{~min}$, and centrifuged at $300 \mathrm{xg}$ for $10 \mathrm{~min}$ at $4^{\circ} \mathrm{C}$. The supernatant was collected and protein concentration was determined using a Bicinchoninic Acid Protein Assay kit (Pierce; Thermo Fisher Scientific, Inc., Waltham, MA, USA). Proteins (50 $\mu \mathrm{g}$ for H2AX; $35 \mu \mathrm{g}$ for all others) were separated by $8 \%$ SDS-PAGE and were transferred onto a polvinylidene fluoride membrane (EMD Millipore, Billerica, MA, USA). Subsequently, the membrane, which was previously treated with $5 \%(\mathrm{w} / \mathrm{v})$ bovine serum albumin (BSA; Sigma-Aldrich; Merck KGaA) for $6 \mathrm{~h}$ at $4^{\circ} \mathrm{C}$ to block non-specific antibody binding, was incubated overnight at $4^{\circ} \mathrm{C}$ with the following specific primary antibodies: Polyclonal anti-PARP (cat. no. 9542) and anti-53BP1 (cat. no. 4937); monoclonal anti-phosphorylated (p)-H2AX (Ser139; cat. no. 9718), anti-p-checkpoint kinase (Chk)1 (Ser345; cat. no. 2348), anti-p-Chk2 (Thr68; cat. no. 2197), anti-p-p53 (Ser15; cat. no. 9286) anti-p-ATM serine/threonine kinase (ATM; Ser1981; cat. no. 5883), anti-p27 Kip1 (cat. no. 3686) and anti-p21 (cat. no. 2947) (all at 
Table I. Olaparib, CBP and BKM120 exert synergistic inhibitory effects on triple-negative breast cancer cell viability.

\begin{tabular}{|c|c|c|c|c|c|c|}
\hline \multirow[b]{2}{*}{ Cell line } & \multicolumn{3}{|c|}{$\begin{array}{l}\mathrm{IC}_{50}(\mu \mathrm{M}) \\
\text { Drug alone }^{\mathrm{a}}\end{array}$} & \multicolumn{3}{|c|}{$\begin{array}{c}\mathrm{IC}_{50}(\mu \mathrm{M}) \\
\text { Drug combination }^{\mathrm{b}}\end{array}$} \\
\hline & Olaparib & CBP & BKM120 & Olaparib & CBP & BKM120 \\
\hline CAL51 & 44.1 & 1.2 & 4.8 & 3.3 & 0.8 & 0.6 \\
\hline MDA-MB-231 & 95.1 & 16.5 & 11.1 & 12.5 & 3.1 & 2.5 \\
\hline
\end{tabular}

${ }^{a}$ Values were obtained using drug sensitivity curves shown in Fig. 1A-C; ${ }^{b}$ Values were obtained using drug sensitivity curves shown in Fig. 1D and E. BKM120, NVP-BKM120; CBP, carboplatin; $\mathrm{IC}_{50}$, half maximal inhibitory concentration.

1:1,000 dilution; all Cell Signaling Technology, Inc., Danvers, MA, USA); polyclonal anti- $\beta$-actin (cat. no. YT0099; at 1:2,000 dilution; ImmunoWay Biotechnology Company, Plano, TX, USA); and monoclonal anti-PARP polymer (PADPR; cat. no. ab14459; at 1:1,000 dilution; Abcam, Cambridge, UK). After washing, the membrane was incubated with anti-rabbit or anti-mouse secondary antibodies (cat. nos. 7074 and 7076 , respectively; Cell Signaling Technology, Inc.) for $2 \mathrm{~h}$ at room temperature. Blots were visualized using enhanced chemiluminiscence (Pierce; Thermo Fisher Scientific, Inc.) according to the manufacturer's protocol. Semi-quantification of blots was performed using ImageJ software version 1.41o (National Institutes of Health, Bethesda, MD, USA).

Immunofluorescence. Cells were washed with $1 \mathrm{X}$ PBS, fixed with methanol and acetone (1:1, v:v) for $5 \mathrm{~min}$, and then blocked with $3 \%$ BSA for $1 \mathrm{~h}$ at room temperature. Cells were incubated with the following antibodies for $12 \mathrm{~h}$ at $4^{\circ} \mathrm{C}$ : Anti-BRCA1 (cat. no. YT0519), anti-53BP1 (cat. no. YT0024) and anti-DNA repair protein RAD51 homolog 1 (RAD51; cat. no. YT3967) (all ImmunoWay Biotechnology Company), and $\gamma$-H2AX (Ser139; cat. no. 9718; Cell Signaling Technology, Inc.). Antibodies were used at a 1:500 dilution in 1\% BSA. After washing, samples were incubated with Alexa Fluor 488-conjugated secondary antibody (1:500 dilution; cat. no. 913921; Invitrogen; Thermo Fisher Scientific, Inc.) for $1 \mathrm{~h}$ at room temperature, after which, nuclei were stained with DAPI (Sigma-Aldrich; Merck KGaA) for $5 \mathrm{~min}$. Cells were washed with 1X PBS and were observed under a fluorescence microscope (Carl Zeiss AG, Oberkochen, Germany).

Statistical analysis. Data are presented as the means \pm standard deviation. Differences between groups were analyzed by one-way analysis of variance and Dunnett's test using SPSS 22.0 software (IBM Corp., Armonk, NY, USA). P<0.05 (two-tailed) was considered to indicate a statistically significant difference.

\section{Results}

Treatment with a combination of olaparib, CBP and BKM120 synergistically inhibits TNBC cell growth. In order to assess the inhibitory effects of the three drugs on the growth of MDA-MB-231 and CAL51 cells, the present study determined the half maximal inhibitory concentration $\left(\mathrm{IC}_{50}\right)$ values after $72 \mathrm{~h}$ using MTT assays (Table I). Olaparib, CBP and BKM120 exhibited dose-dependent inhibition of MDA-MB-231 and CAL51 cells (Fig. 1A-C); however, the inhibitory effects of single drug treatment were limited. CBP and BKM120 had relatively low $\mathrm{IC}_{50}$ values in CAL51 cells $(1.2$ and $4.8 \mu \mathrm{M}$, respectively). Conversely, the toxicity of olaparib in CAL51 and MDA-MB-231 cells was modest $\left(\mathrm{IC}_{50}: 44.1\right.$ and $95.1 \mu \mathrm{M}$, respectively). In order to determine whether olaparib toxicity could be increased when used in combination, cells were treated with all three drugs together at various concentrations. Notably, the combination indexes were $<0.9$ (Fig. 1D and E), thus indicating a synergistic inhibitory effect that was stronger in MDA-MB-231 than in CAL51 cells, which could limit the adverse effects of olaparib in clinical use (16). As expected, the $\mathrm{IC}_{50}$ values of each drug when used in combination were much lower than those obtained for individual drugs (Table I) and, this effect was only observed in TNBC cells; no synergistic effect was detected in MCF-7 cells (CI values $>1.1$ ) (Fig. 1F).

To evaluate the efficacy of the three drug combination on colony formation, cell cultures were treated for 10 days with drugs, either alone or in combination, and were then stained with crystal violet (Fig. 2). Confirming the results of the aforementioned short-term sensitivity assays, individual drugs inhibited proliferation of TNBC cells to some extent and olaparib was the least toxic drug. A combination of two drugs improved inhibition of MDA-MB-231 and CAL51 cell proliferation; the inhibitory effect was strongest in response to olaparib and CBP. Notably, the strongest inhibitory effect was observed when the three drugs were used in combination.

The results of these short- and long-term drug assays indicated that olaparib, CBP and BKM120 may exert a strong synergistic inhibitory effect on TNBC cells.

Olaparib, CBP and BKM120 affect cell cycle progression in $T N B C$ cells. In order to gain insight into the possible mechanisms underlying the toxic effects of olaparib, CBP and BKM120 on TNBC cells, the present study assessed their effects on cell cycle progression by flow cytometry (Fig. 3). As single drugs, olaparib and CBP led to an increase in the proportion of CAL51 cells at the $\mathrm{G}_{2} / \mathrm{M}$ phase of the cell cycle (4.6 and $9.2 \%$ increase compared with the control group respectively), whereas in MDA-MB-231 cells this was only 
A

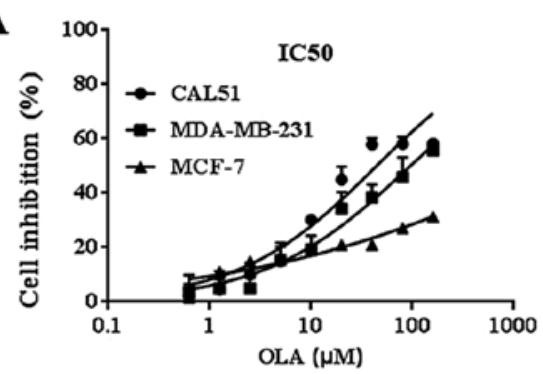

C

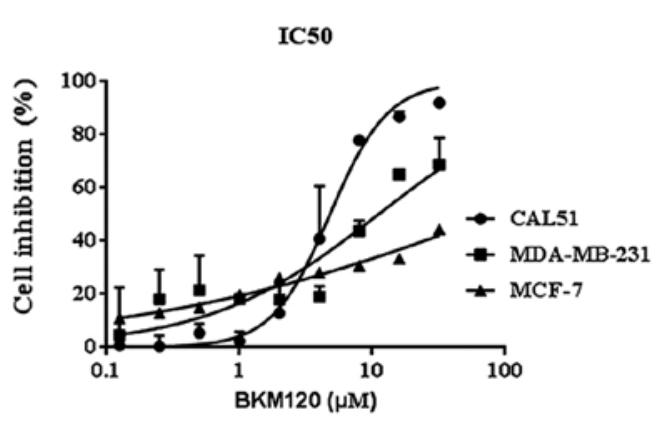

E

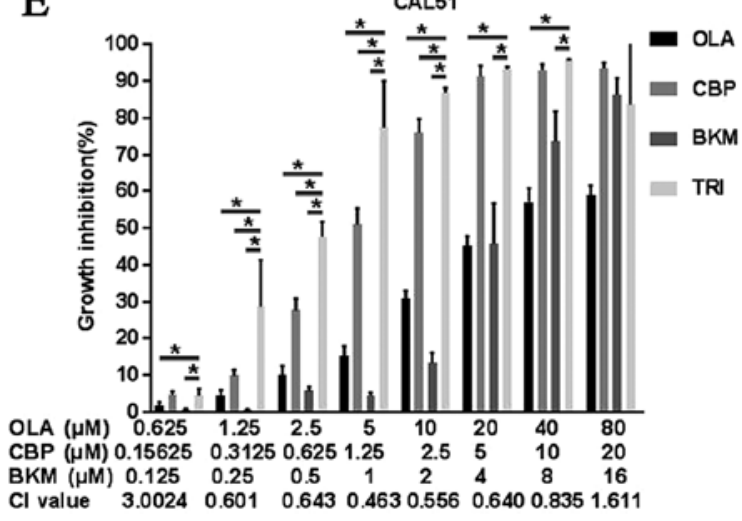

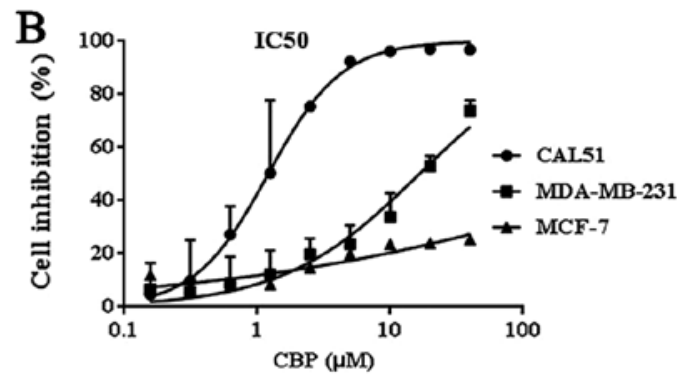

D

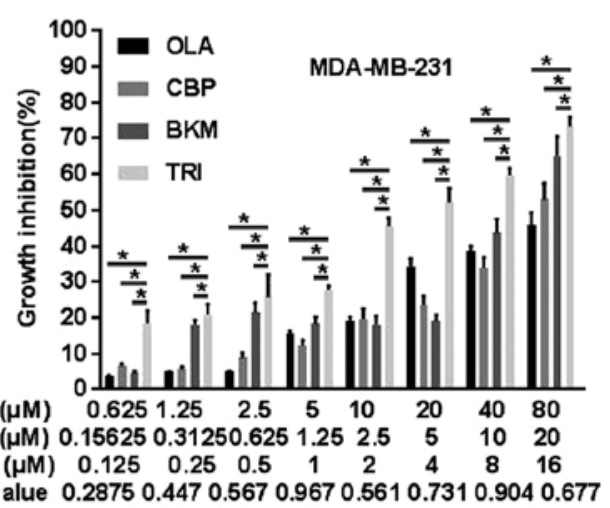

F

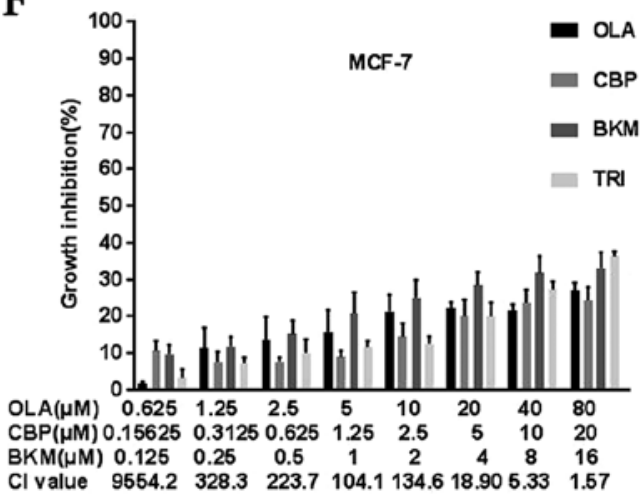

Figure 1. OLA, CBP and BKM exert synergistic toxicity on TNBC cells. MTT assays were used to determine toxicity profiles. TNBC MDA-MB-231 and CAL51 cells, and the non-TNBC cell line MCF-7, were treated with (A) CBP, (B) BKM or (C) OLA alone, or (D-F) in combination for $72 \mathrm{~h}$. Data are presented as the means \pm standard deviation from three independent experiments. ${ }^{*} \mathrm{P}<0.05$. BKM, NVP-BKM120; CBP, carboplatin; CI, combination index; IC ${ }_{50}$, half maximal inhibitory concentration; OLA, olaparib; TNBC, triple-negative breast cancer.

apparent with olaparib $(6.5 \%$ increase compared with the control group), as CBP produced an increase in the proportion of cells in $\mathrm{S}$ phase (10.1\% increase compared with the control group). In both cells, BKM120 had little effect. Although there is no conclusive evidence regarding this differential effect between cell lines, it may be hypothesized that this is likely due to their different doubling times; CAL51 cells divide faster than MDA-MB-231 cells. Therefore, the effects of some drugs are seen later in CAL51 $\left(\mathrm{G}_{2} / \mathrm{M}\right)$ than in MDA-MB-231 cells (S phase). Combining olaparib and CBP led to an increase in the proportion of cells in $\mathrm{G}_{2} / \mathrm{M}$ phase in CAL51 cells (16.3\% increase) and S phase in MDA-MB-231 cells $(10.1 \%$ increase). As expected, the strongest effect on cell cycle arrest was observed when the three drugs were combined: CAL51 cells exhibited a $20.6 \%$ increase in the number of cells at $\mathrm{G}_{2} / \mathrm{M}$ phase, whereas MDA-MB-231 cells exhibited a $14.2 \%$ increase in the number of cells at $S$ phase, all compared with the control group.
Olaparib, CBP and BKM120 cause DNA damage in TNBC cells. Due to their mode of action and toxicity in TNBC cells, the present study aimed to determine the effects of the three treatments on the expression of key molecules involved in DNA damage (Fig. 4). Phosphorylation of the histone variant $\mathrm{H} 2 \mathrm{AX}$ serves a key role in the DNA damage response and its expression is routinely used to detect genotoxic effects. In addition, PARP inhibition leads to the accumulation of DNA DSBs (19) The phosphorylated levels of H2AX were increased in both MDA-MB-231 and CAL51 cells following treatment with each of the three drugs, whereas the levels of PADPR, which is synthesized by PARP, were decreased in both cell lines; as expected, it was more markedly decreased following the addition of BKM120 (Fig. 4A and B). Phosphorylation of the checkpoint kinases Chk1 and Chk2, whose activation by ATM results in cell cycle arrest and cell death (confirmed by PARP cleavage), was increased following treatment with olaparib, CBP and BKM120 (Fig. 4A and B). 


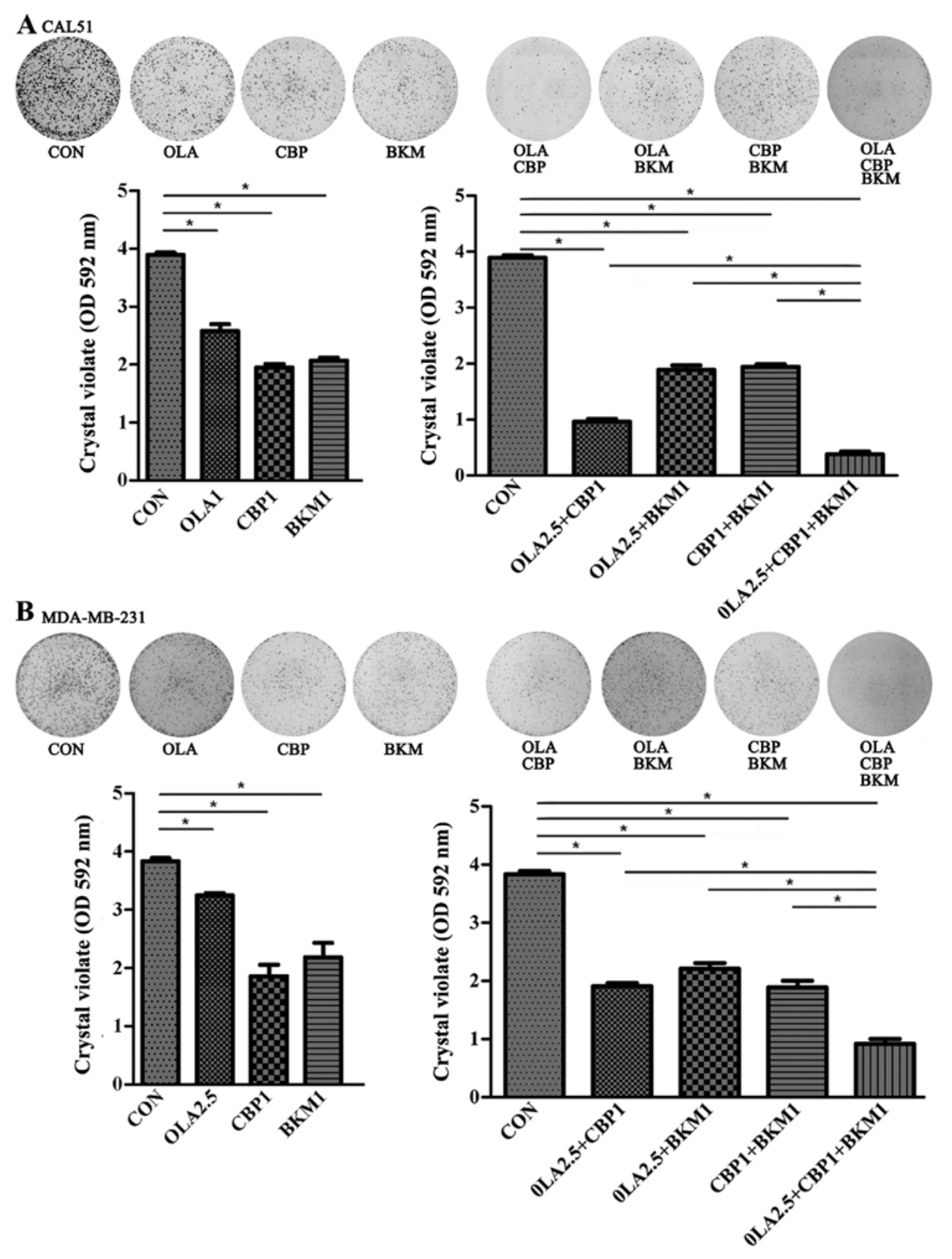

Figure 2. OLA, CBP and BKM exert synergistic inhibitory effects on triple-negative breast cancer cell proliferation. (A) CAL51 and (B) MDA-MB-231 cells were seeded in 6-well plates and after 1 day were treated with the drugs, either alone or in combination; cells were treated for 10 days before being stained with crystal violet. Concentrations used were: OLA, $2.5 \mu \mathrm{M}$; CBP, $1 \mu \mathrm{M} ; \mathrm{BKM}, 1 \mu \mathrm{M}$. The dye was solubilized and the optical density was measured at $592 \mathrm{~nm}$. Images are representative of three experiments. Numerical data are presented as the means \pm standard deviation of three independent experiments. "P<0.05. BKM, NVP-BKM120; CBP, carboplatin; CON, control (vehicle); OD, optical density; OLA, olaparib.

Phosphorylation of Chk2 was more evident in CAL51 cells than in MDA-MB-231 cells, indicating that the latter may not be as sensitive to olaparib and CBP as the former, as expression levels were only altered in the groups treated with high concentrations. It is possible that BKM120 toxicity in MDA-MB-231 cells is associated with other mechanisms than those affecting Chk2 phosphorylation.

Since the formation of RAD51 foci is considered a marker of HR DNA repair $(19,20)$ and $\gamma-\mathrm{H} 2 \mathrm{AX}$ foci are considered to be a sensitive and selective signal for the existence of DSBs (21), the present study monitored foci formation in MDA-MB-231 and CAL51 cells after single, double and triple drug combinations. CAL51 and MDA-MB-231 cells treated with a combination of olaparib, CBP and BKM120 exhibited very low RAD51 foci (marker of HR DNA repair), which was reduced compared with in response to other certain treatments, particularl CBP, when used singly or in combination, i.e. olaparib and CBP (Fig. 5). $\gamma$-H2AX foci formation (a marker of DSBs) was high when olaparib was combined with either CBP or CBP and BKM120, although CBP alone produced a higher level of DSBs (Fig. 5). Overall, these findings suggested that cells receiving the triple drug combination may exhibit less active HR repair leading to cell death.

Overall, the three drugs used in this study, olaparib, CBP, and BKM120, may exert their toxic effects on TNBC cells by producing DNA damage. 

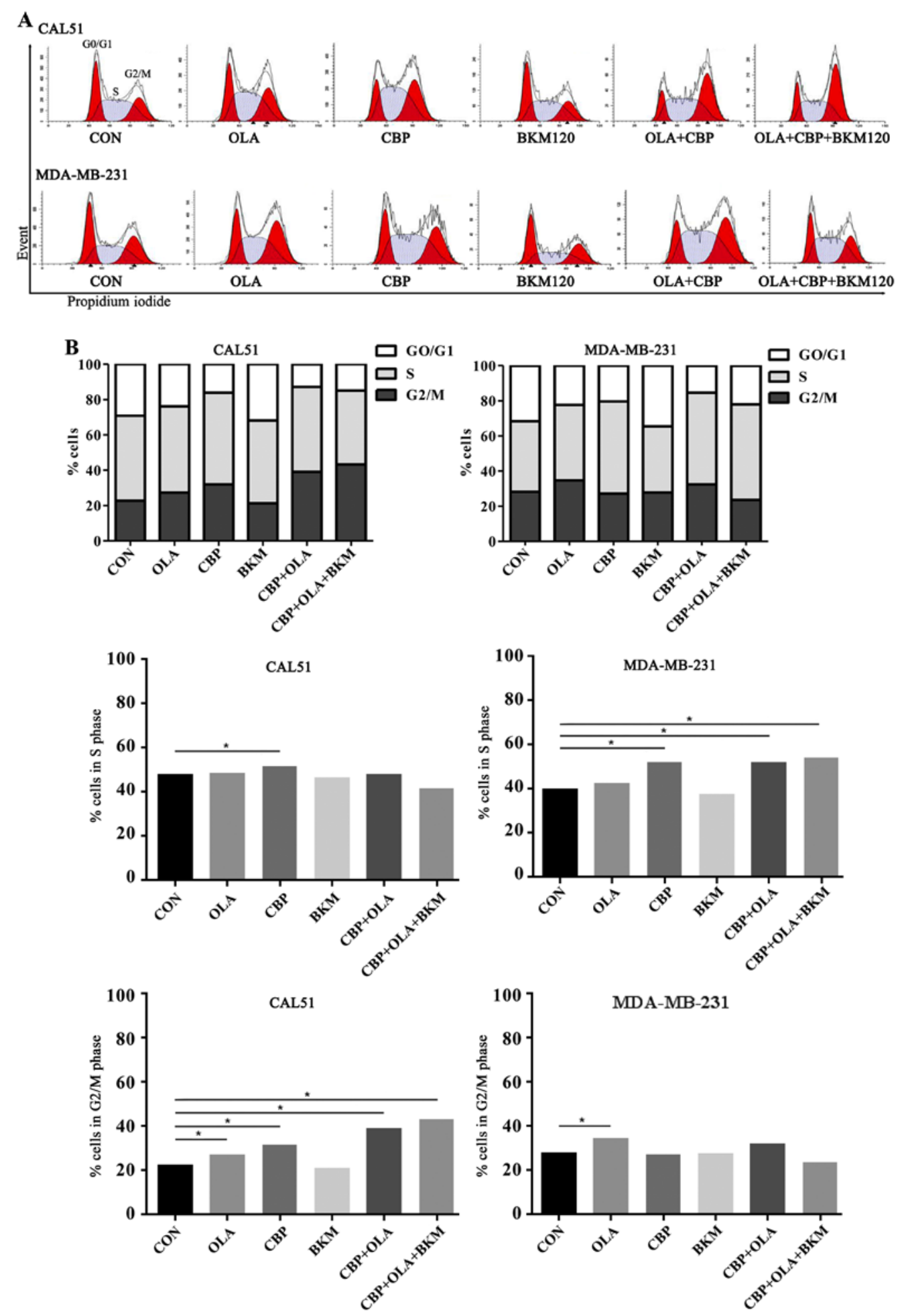

Figure 3. OLA, CBP and BKM block cell cycle progression in triple-negative breast cancer cells. Cells were treated with OLA $(1.25 \mu \mathrm{M}), \mathrm{CBP}(0.5 \mu \mathrm{M})$ and $\operatorname{BKM}(0.5 \mu \mathrm{M})$, alone or in combination, for $48 \mathrm{~h}$ and were then stained with PI. (A) Flow cytometry plots indicating cell cycle phases. The rugged line represents cells detected by flow cytometry after PI staining; the smooth line and red peaks are the best fits for cell cycle phases obtained using the flow cytometry software (ModFit LT; Verity Software House, Inc., Topsham, ME, USA). (B) Histogram data are presented as the means of three independent experiments. For clarity, error bars have been omitted in histograms showing bars with three cell cycle phases (typical variation between experiments: $\pm 10 \%$ ). "P<0.05. BKM, NVP-BKM120; CBP, carboplatin; CON, control (vehicle); OD, optical density; OLA, olaparib; PI, propidium iodide.

BKM120 treatment increases NHEJ DNA repair and growth inhibition of TNBC cells. Since BKM120 leads to an increase in NHEJ DNA repair (22), the present study evaluated the functionality of the NHEJ repair axis following treatment with the combination of the three drugs. The aggregation of 53BP1 helps to amplify the ATM signal and activation of cell cycle check points. When DSBs occur, ATM initiates cell cycle check points by phosphorylation of $\mathrm{p} 53$ and other cell cycle regulatory proteins (14). As expected, the expression of 53BP1, p27, p21 and p-ATM was increased in MDA-MB-231 and CAL51 cells 
A
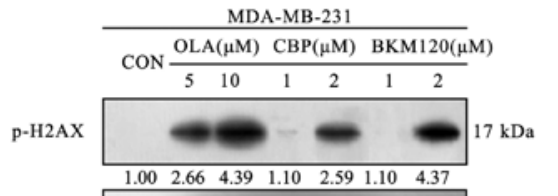

PADPR Dam * * $120 \mathrm{kDa}$ $\begin{array}{lllllll}1.00 & 0.93 & 0.42 & 0.56 & 0.51 & 0.19 & 0.14\end{array}$

p-CHK
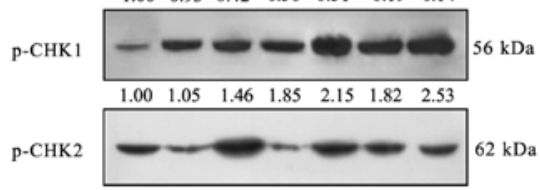

$\begin{array}{lllllll}1.00 & 0.47 & 1.53 & 0.56 & 1.23 & 0.97 & 0.92\end{array}$

p-ATM

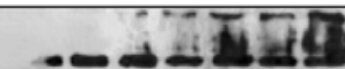

$350 \mathrm{kDa}$

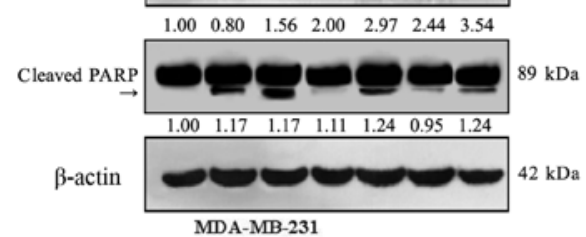

B
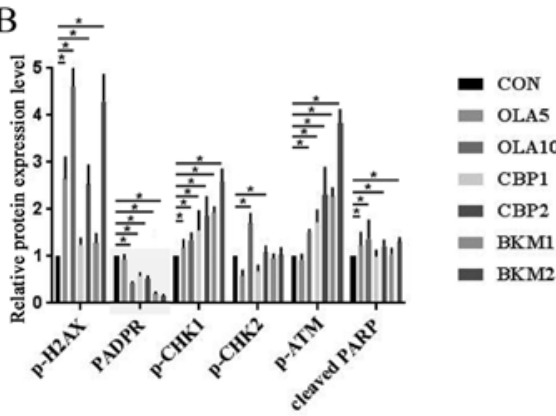

C

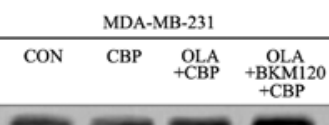

53BPl $=-200 \mathrm{kDa}$
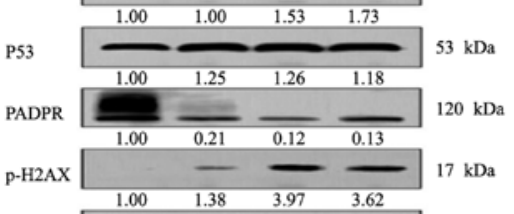

p-ATM $\frac{1.00}{1.00} \frac{1.38}{0.92} \frac{3.97}{1.36} \frac{3.62}{1.47} 350 \mathrm{kDa}$
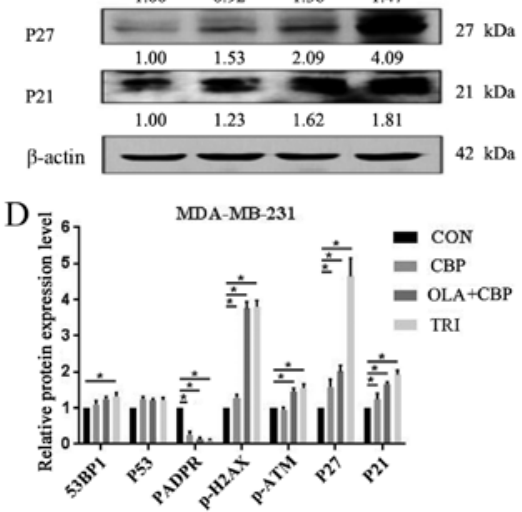

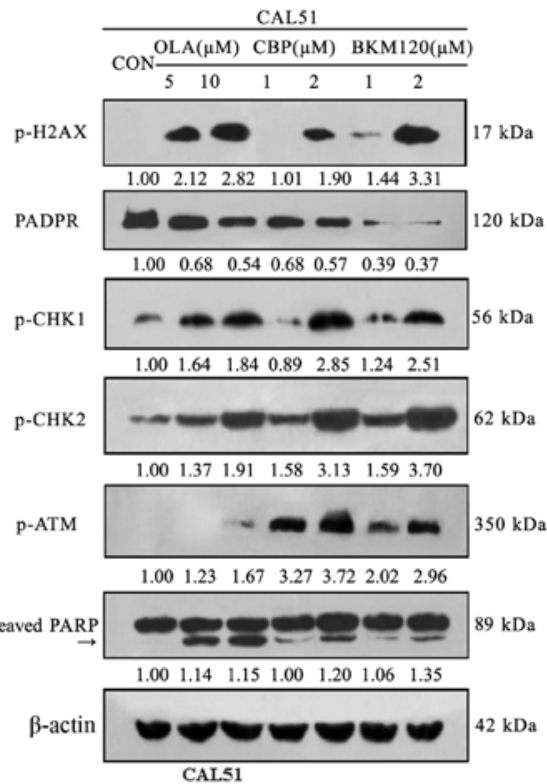

CAL51
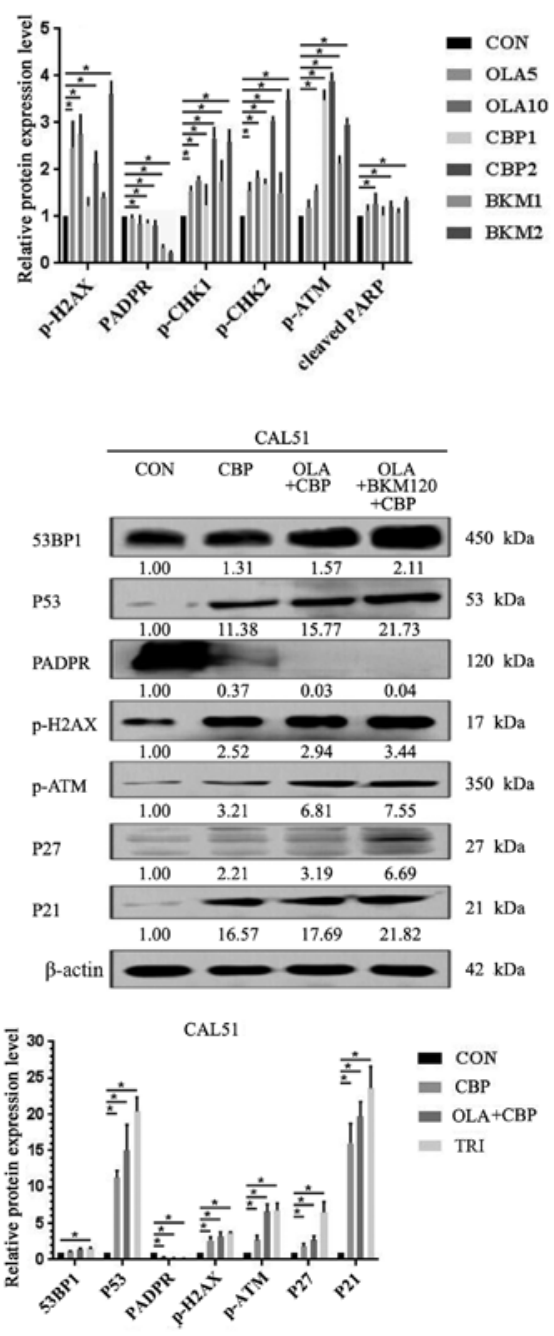

Figure 4. OLA, CBP and BKM exert toxic effects on triple-negative breast cancer cells by producing DNA damage. (A and B) Cells were treated with vehicle (CON), OLA, CBP or BKM for $48 \mathrm{~h}$, and protein expression was determined by western blotting. (A) p-ATM antibody recognizes a non-specific band (heavier than $350 \mathrm{kDa}$ ) in MDA-MB-231 cells; the $350 \mathrm{kDa}$ band is indicated by an arrow. Cleaved PARP is indicated with an arrow. BKM increases NHEJ DNA repair. (C and D) Cells were treated with $\mathrm{CBP}(0.5 \mu \mathrm{M})$ alone or in combination with OLA $(1.25 \mu \mathrm{M})$ and $\mathrm{BKM}(0.5 \mu \mathrm{M})$ for $24 \mathrm{~h}$, and protein expression was determined by western blotting. $\beta$-actin was used as a loading control. Representative images of three independent blots are shown. Semi-quantification of blots was performed using ImageJ software (National Institutes of Health, Bethesda, MD, USA) and values are normalized to those of $\beta$-actin and expressed as relative to those of untreated cells. Band intensity is indicated below each gel track and histogram data are presented as the means \pm standard deviation of three blots. "P<0.05. ATM, ATM serine/threonine kinase; BKM, NVP-BKM120; CBP, carboplatin; Chk, checkpoint kinase; CON, control (vehicle); OLA, olaparib; p-, phosphorylated; PARP, poly(ADP-ribose) polymerase. 

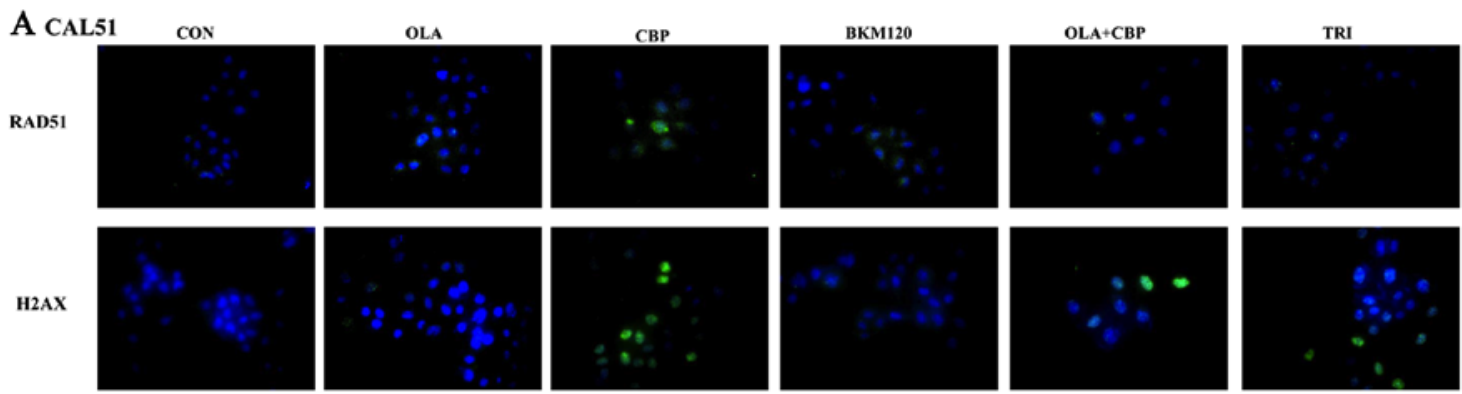
CAL51
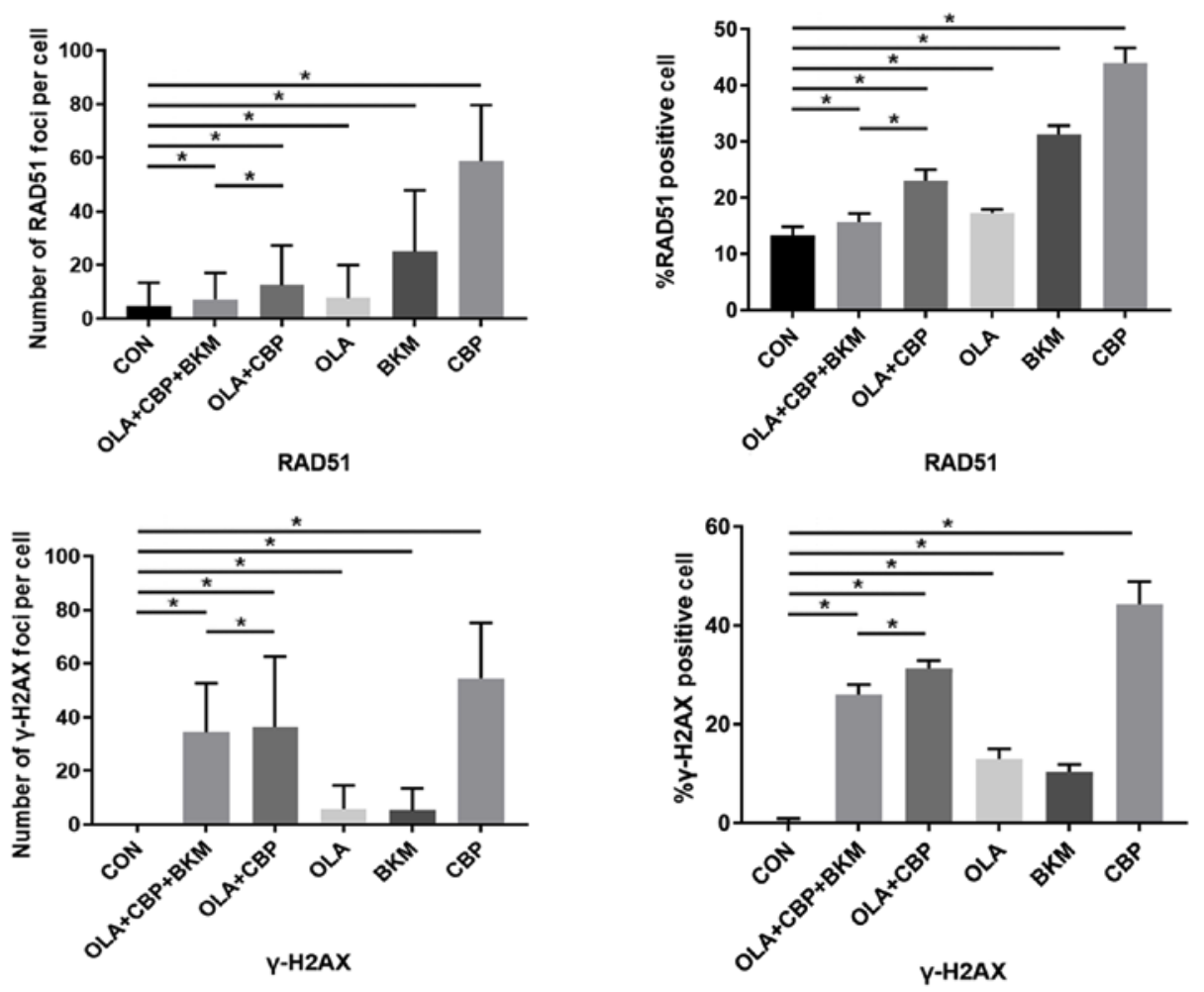

Figure 5. Combination of OLA, CBP and BKM promotes DNA damage in triple-negative breast cancer cells. (A) Cells (CAL51) were treated with vehicle (CON), 1.2 $\mu \mathrm{M}$ OLA, $0.5 \mu \mathrm{M}$ CBP, $0.5 \mu \mathrm{M}$ BKM or a combination, for $48 \mathrm{~h}$. RAD51 and $\gamma$-H2AX expression was visualized by immunofluorescence using primary specific antibodies and Alexa Fluor 488-conjugated secondary antibodies. Nuclei were stained with DAPI. The percentage of RAD51 and $\gamma$-H2AX positive cells ( $\geq 5$ foci) and the number of RAD51 and $\gamma$-H2AX foci/cell were determined by counting at least 100 cells from each sample. Images were captured at $\mathrm{x} 400$ magnification.. Data are presented as the mean \pm standard deviation of three independent experiments. ${ }^{*} \mathrm{P}>0.05$. BKM, NVP-BKM120; CBP, carboplatin; CON, control (vehicle); OLA, olaparib; RAD51, DNA repair protein RAD51 homolog 1.

treated with a combination of the three drugs (Fig. 4C and D). In addition, CAL51 cells exhibited an increase in p53 expression, which was not observed in MDA-MB-231 cells as they possess mutated $\mathrm{p} 53$. The increase in 53BP1 expression in the combination group compared with in the olaparib and CBP group was also confirmed by immunofluorescence (Fig. 6). In addition, a decrease in BRCA1 expression was detected in the combination group compared with in the olaparib and CBP group (Fig. 6), which may lead to a decrease in HR repair (23), and thus an increase in response to the PARP inhibitor.

These findings indicated that a combination of olaparib, CBP and BKM120 may lead to an increase in NHEJ DNA repair, contributing to growth inhibition in TNBC cells.

\section{Discussion}

TNBC refers to a heterogeneous group of tumors that possess aggressive clinical features (24) and lack targeted therapeutic options. TNBC is currently treated with standard chemotherapeutics, including CBP and other platinum drugs (25). In addition, $\sim 15 \%$ of TNBC cases harbor a germline mutation in BRCA1 or BRCA $2 ;>80 \%$ of BRCA1 mutation-associated breast cancer cases and $35 \%$ of BRCA2 mutation-associated breast cancer cases possess the TNBC phenotype $(26,27)$. Therefore, therapeutic strategies targeting these pathways are currently being studied. Olaparib is an oral PARP inhibitor that, amongst other effects, blocks base-excision repair by trapping PARP at the site of DNA damage, and leads to the collapse of DNA replication forks and the accumulation of DNA DSBs (28). Furthermore, TNBC frequently presents copy number variations at certain loci, such as those involved in DNA damage repair and PI3K pathways (29). BKM120, which is a pan-class I PI3K inhibitor currently in Phase I/II clinical trials, has demonstrated antiproliferative, pro-apoptotic and antitumor activity in various cell lines, as well as in xenograft models of cancers with or without aberrant PI3K 
B MDA-MB-231
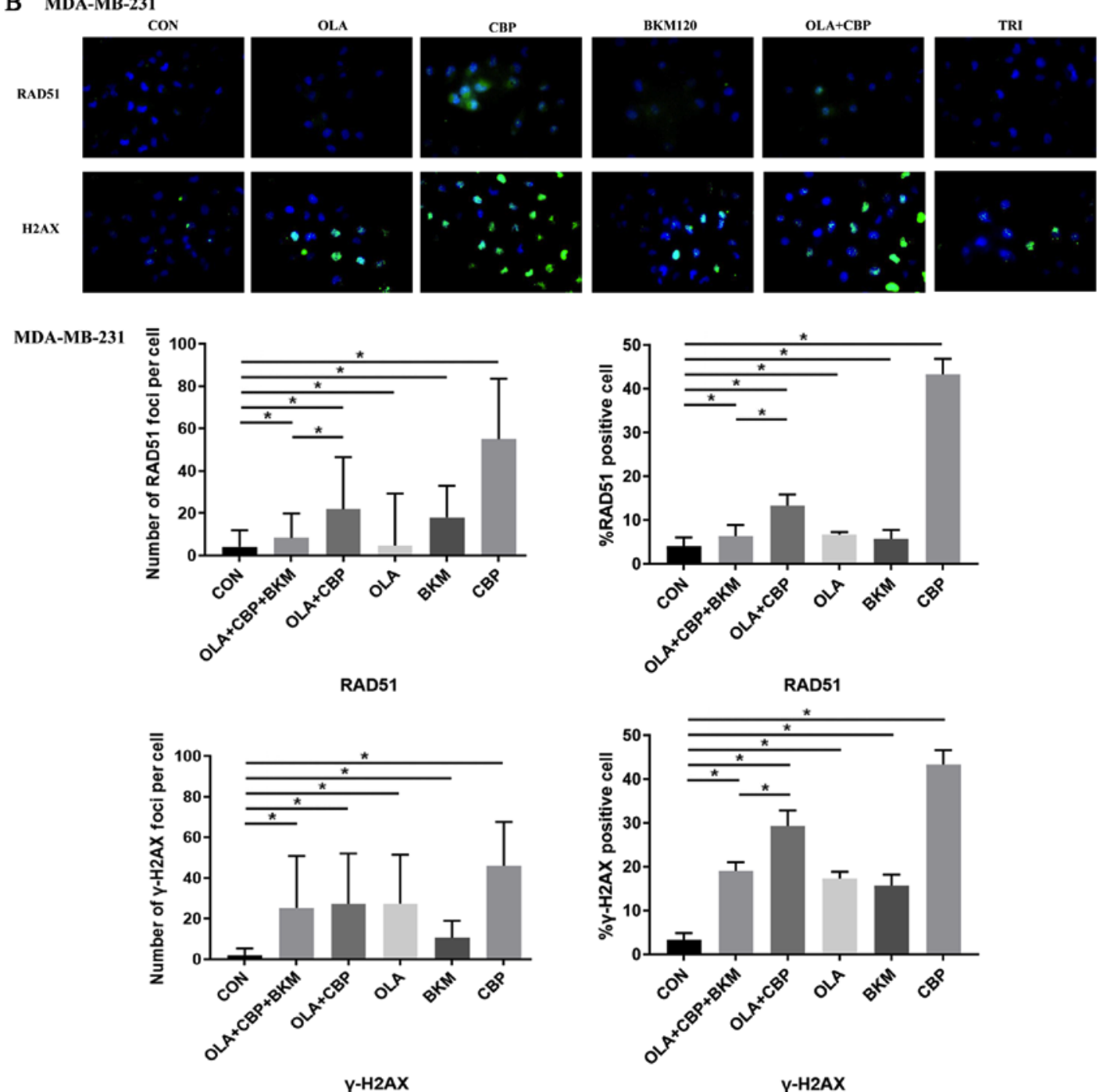

Figure 5. Continued. Combination of OLA, CBP and BKM promotes DNA damage in triple-negative breast cancer cells. (B) Cells (MDA-MB-231) were treated with vehicle (CON), $1.2 \mu \mathrm{M}$ OLA, $0.5 \mu \mathrm{M} \mathrm{CBP}, 0.5 \mu \mathrm{M}$ BKM or a combination, for $48 \mathrm{~h}$. RAD51 and $\gamma$-H2AX expression was visualized by immunofluorescence using primary specific antibodies and Alexa Fluor 488-conjugated secondary antibodies. Nuclei were stained with DAPI. The percentage of RAD51 and $\gamma$-H2AX positive cells ( $\geq 5$ foci) and the number of RAD51 and $\gamma$-H2AX foci/cell were determined by counting at least 100 cells from each sample. Images were captured at $\mathrm{x} 400$ magnification.. Data are presented as the mean \pm standard deviation of three independent experiments. "P>0.05. BKM, NVP-BKM120; CBP, carboplatin; CON, control (vehicle); OLA, olaparib; RAD51, DNA repair protein RAD51 homolog 1.

pathway activation (30). The combination of olaparib and CBP is tolerable and has modest activity in patients with sporadic TNBC (31). The present findings indicated that the combination of CBP, olaparib and BKM120 may exert synergistic inhibitory effects on MDA-MB-231 and CAL51 TNBC cell lines.

DNA damage repair serves an important role in the maintenance of genome stability; however, this same phenomenon can lead to drug resistance in cancer cells. Therefore, blocking the DNA repair pathway is an important method for the treatment of tumors (32). DNA damage can be divided into two types: DNA single-strand breaks (SSBs) and DSBs. In the S phase of the cell cycle, several unrepaired SSBs can lead to disintegration of the duplicating forks and can subsequently result in DSBs. The repair of DSBs in DNA occurs through two methods of repair, HR and NHEJ (33). HR repair uses high homologous sister chromosome fragments as a template to repair damaged DNA, and is considered an error-free repair mechanism (34). NHEJ is an error-prone repair mechanism, which results in the accumulation of damaged DNA that can cause cell death (33). NHEJ begins in the $G_{1}$ phase, in which the accuracy of repair is low, whereas HR begins in the $S / G_{2}$ phase, in which the accuracy of repair is high. Furthermore, the repair of DSBs is strictly regulated by the cell cycle. Deficient HR repair leads to activation of alternate DNA repair pathways, including the base excision repair and NHEJ pathways, which require PARP. HR repair dysfunction sensitizes cells to PARP, which leads to further chromosomal instability, cell cycle arrest and apoptosis $(35,36)$; TNBC normally expresses high levels of PARP-1 $(37,38)$. Therefore, olaparib can induce DSBs and inhibit HR repair, whereas PI3K inhibitors can influence cell cycle progression, inhibit HR repair and enhance NHEJ repair (39). Conversely, BKM120 can induce the expression of BRCA1 (40); therefore, BKM120 may promote HR repair and sensitize TNBC to PARP inhibition.

In summary, the present study demonstrated that a combination of three drugs, olaparib (a PARP inhibitor), CBP (a drug which crosslinks with purine bases in the DNA, interfering 

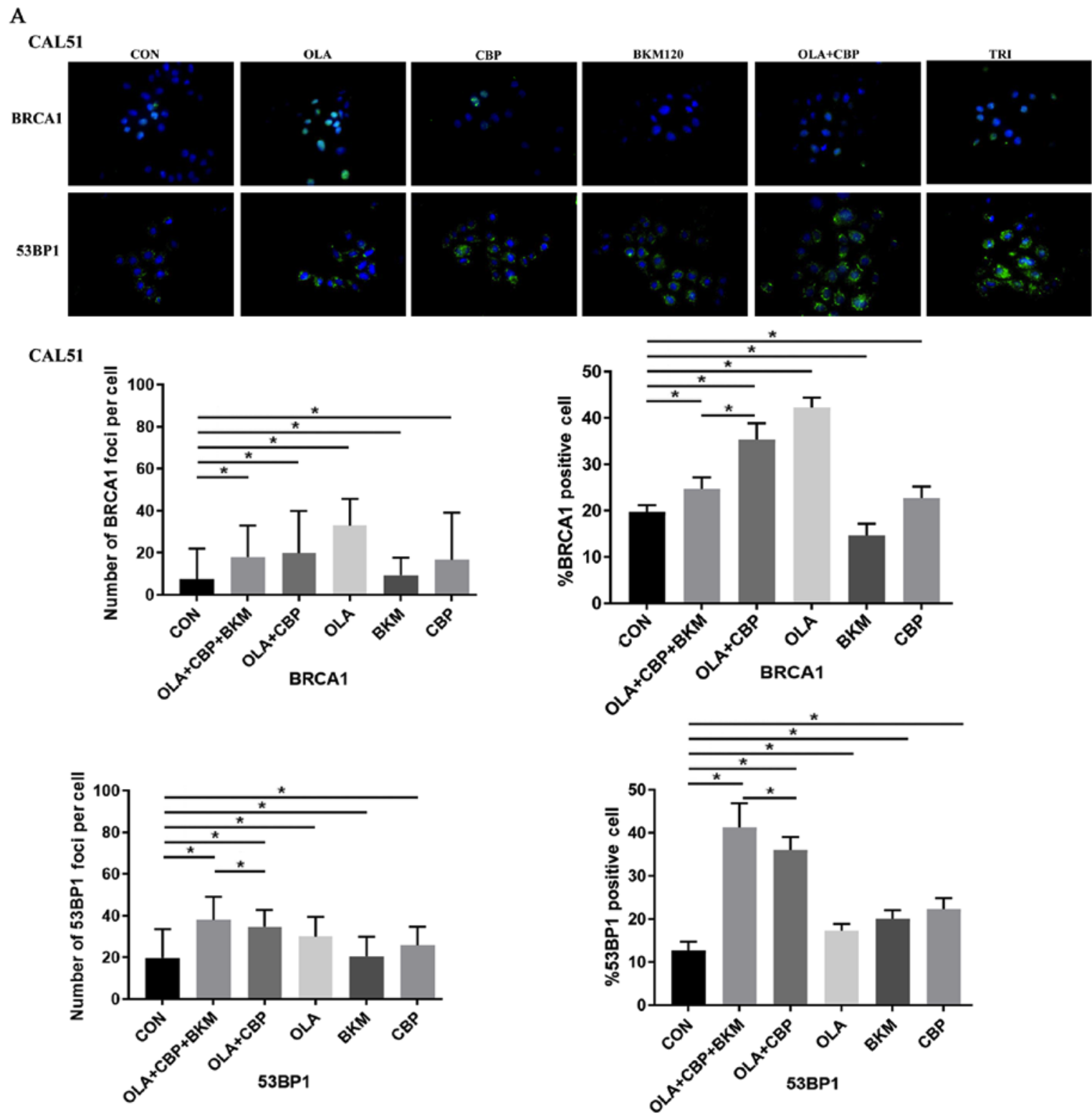

Figure 6. Immunofluorescence of BRCA1 and 53BP1. (A) Cells (CAL51) were treated with vehicle (CON), $1.2 \mu \mathrm{M}$ OLA, $0.5 \mu \mathrm{M}$ CBP, $0.5 \mu \mathrm{M}$ BKM or a combination, for $48 \mathrm{~h}$. BRCA1 and 53BP1 expression was visualized by immunofluorescence using primary specific antibodies and Alexa Fluor 488-conjugated secondary antibodies. Nuclei were stained with DAPI. The percentage of BRCA1 and 53BP1 positive cells ( $\geq 5$ foci) and the number of BRCA1 and 53BP1 foci/ cell were determined by counting $\geq 100$ cells from each sample. Images were captured at $x 400$ magnification.. Data are presented as the mean \pm standard deviation of three independent experiments. "P>0.05. BKM, NVP-BKM120; BRCA1, BRCA1, DNA repair-associated; CBP, carboplatin; CON, control (vehicle); OLA, olaparib.

with DNA repair mechanisms and producing DNA damage) and BKM120 (a pan-class I PI3K inhibitor) act synergistically on TNBC cells via DNA damage, enhancing NHEJ and inhibiting HR. As TNBC lacks targeted therapies, there is an urgent need to identify novel effective treatments for this type of breast cancer. The present study provided a strong rationale to explore the therapeutic use of olaparib in combination with CBP and BKM120, first in animal models, and later in clinical trials on patients with TNBC.

\section{Acknowledgements}

The authors would like to thank AstraZeneca for the generous gift of olaparib, and Dr S. Raguz (Imperial College London) for English language support. Part of this study was presented at the ASCO 2018 Annual Meeting (Abstract no. e12535).

\section{Funding}

The present study was supported by the Chinese National Natural Sciences Foundation (grant no. 81672623 to ZJ) and the National Science and Technology Support program (grant no. 2015BAI12B15 to ZJ).

\section{Availability of data and materials}

All data generated or analyzed during this study are included in this publication article. 

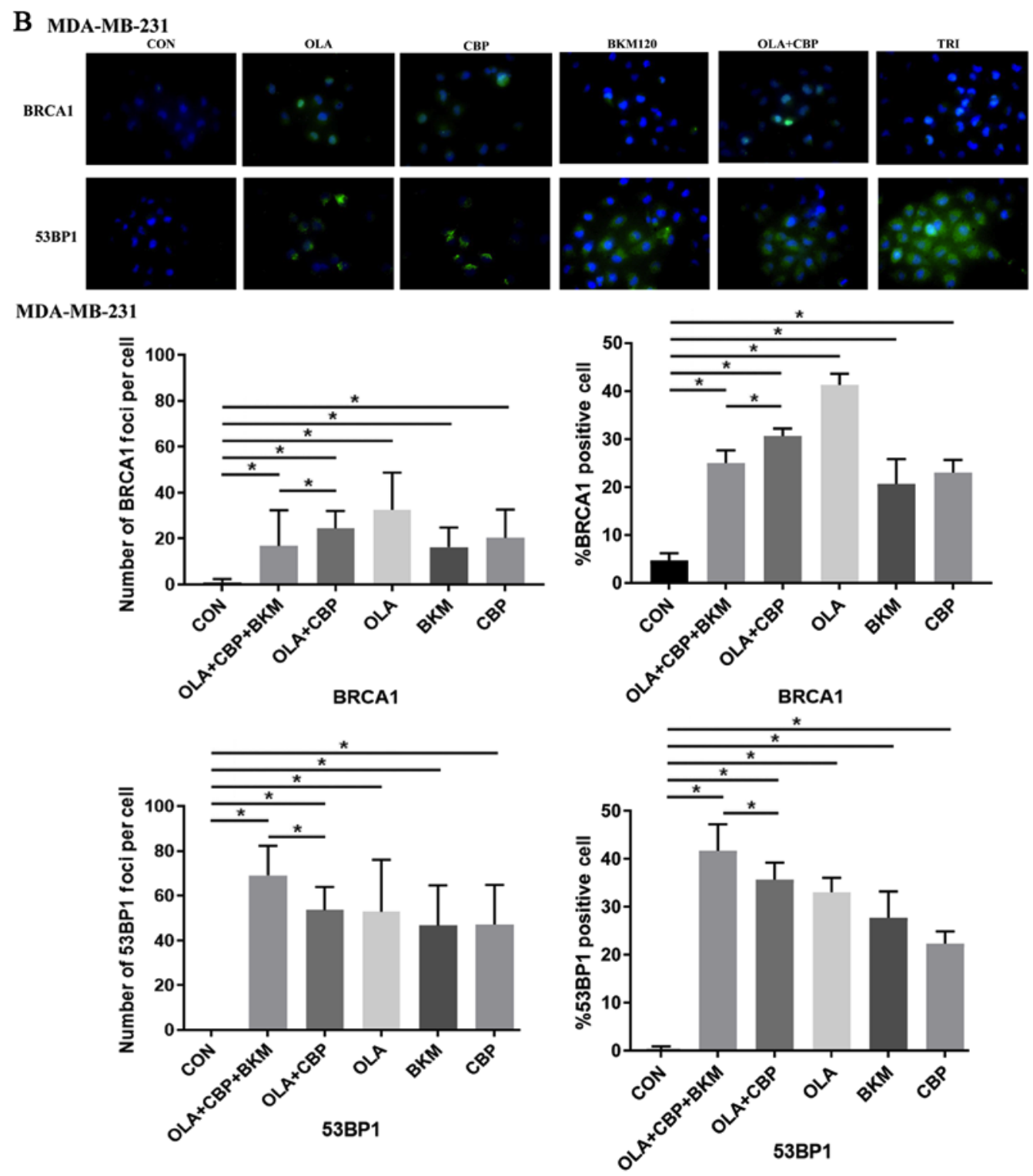

Figure 6. Continued. Immunofluorescence of BRCA1 and 53BP1. (B) Cells (MDA-MB-231) were treated with vehicle (CON), $1.2 \mu \mathrm{M}$ OLA, $0.5 \mu \mathrm{M}$ CBP, $0.5 \mu \mathrm{M}$ BKM or a combination, for $48 \mathrm{~h}$. BRCA1 and 53BP1 expression was visualized by immunofluorescence using primary specific antibodies and Alexa Fluor 488-conjugated secondary antibodies. Nuclei were stained with DAPI. The percentage of BRCA1 and 53BP1 positive cells ( $\geq 5$ foci) and the number of BRCA1 and 53BP1 foci/cell were determined by counting $\geq 100$ cells from each sample. Images were captured at $x 400$ magnification.. Data are presented as the mean \pm standard deviation of three independent experiments. "P>0.05. BKM, NVP-BKM120; BRCA1, BRCA1, DNA repair-associated; CBP, carboplatin; CON, control (vehicle); OLA, olaparib.

\section{Authors' contributions}

JZ designed the research; HZ and YH designed the experiments; HZ and QY performed the research; QY performed the cell culture and MTT assays; HZ performed western blotting and immunofluorescence; YH performed the cell cycle analysis; HZ, YH and JZ wrote the manuscript. All authors read and approved the final manuscript.

\section{Ethics approval and consent to participate}

Not applicable.

\section{Patient consent for publication}

Not applicable.

\section{Competing interests}

The authors declare that they have no competing interests.

\section{References}

1. Dawson SJ, Provenzano E and Caldas C: Triple negative breast cancers: Clinical and prognostic implications. Eur J Cancer 45: 27-40, 2009.

2. Murai J, Huang SYN, Das BB, Renaud A, Zhang Y, Doroshow JH, Ji J, Takeda S and Pommier Y: Trapping of PARP1 and PARP2 by clinical PARP inhibitors. Cancer Res 72: 5588-5599, 2012.

3. Rouleau M, Patel A, Hendzel MJ, Kaufmann SH and Poirier GG: PARP inhibition: PARP1 and beyond. Nat Rev Cancer 10: 293-301, 2010.

4. Liu P, Cheng H, Roberts TM and Zhao JJ: Targeting the phosphoinositide 3-kinase pathway in cancer. Nat Rev Drug Discov 8: 627-644, 2009.

5. Fruman DA and Rommel C: PI3K and cancer: Lessons, challenges and opportunities. Nat Rev Drug Discov 13: 140-156, 2014. 
6. Gopal AK, Kahl BS, de Vos S, Wagner-Johnston ND, Schuster SJ, Jurczak WJ, Flinn IW, Flowers CR, Martin P, Viardot A, et al: $\mathrm{PI} 3 \mathrm{~K} \delta$ inhibition by idelalisib in patients with relapsed indolent lymphoma. N Engl J Med 370: 1008-1018, 2014.

7. BurgerMT,Pecchi S, Wagman A, NiZJ, Knapp M, Hendrickson T, Atallah G, Pfister K, Zhang Y, Bartulis S, et al: Identification of NVP-BKM120 as a potent, selective, orally bioavailable class I PI3 kinase inhibitor for treating cancer. ACS Med Chem Lett 2: 774-779, 2011.

8. Maira SM, Pecchi S, Huang A, Burger M, Knapp M, Sterker D, Schnell C, Guthy D, Nagel T, Wiesmann M, et al: Identification and characterization of NVP-BKM120, an orally available pan-class I PI3-kinase inhibitor. Mol Cancer Ther 11: 317-328, 2012.

9. Brachmann SM, Kleylein-Sohn J, Gaulis S, Kauffmann A, Blommers MJ, Kazic-Legueux M, Laborde L, Hattenberger M, Stauffer F, Vaxelaire J, et al: Characterization of the mechanism of action of the pan class I PI3K inhibitor NVP-BKM120 across a broad range of concentrations. Mol Cancer Ther 11: 1747-1757, 2012.

10. Juvekar A, Burga LN, Hu H, Lunsford EP, Ibrahim YH, Balmañà J, Rajendran A, Papa A, Spencer K, Lyssiotis CA, et al: Combining a PI3K inhibitor with a PARP inhibitor provides an effective therapy for $B R C A 1$-related breast cancer. Cancer Discov 2: 1048-1063, 2012.

11. Matulonis U, Wulf GM, Birrer MJ, Westin SN, Faroog S, Bell-McGuin KM, Obermayer E, Whalen C, Spagnoletti T, Luo W, et al.: Phase I study of oral BKM120 and oral olaparib for high-grade serous ovarian cancer (HGSC) or triple-negative breast cancer (TNBC). Ann Oncol 28: 512-518, 2017.

12. Isakoff SJ, Mayer EL, He L, Traina TA, Carey LA, Krag KJ, Rugo HS, Liu MC, Stearns V, Come SE, et al: TBCRC009: A multicenter phase II clinical trial of platinum monotherapy with biomarker assessment in metastatic triple-negative breast cancer. J Clin Oncol 33: 1902-1909, 2015.

13. Weichselbaum RR, Ishwaran H, Yoon T, Nuyten DS, Baker SW, Khodarev N, Su AW, Shaikh AY, Roach P, Kreike B, et al: An interferon-related gene signature for DNA damage resistance is a predictive marker for chemotherapy and radiation for breast cancer. Proc Natl Acad Sci USA 105: 18490-18495, 2008.

14. Daley JM and Sung P: 53BP1, BRCA1, and the choice between recombination and end joining at DNA double-strand breaks. Mol Cell Biol 34: 1380-1388, 2014.

15. O'Donovan PJ and Livingston DM: BRCA1 and BRCA2: Breast/ovariancancer susceptibility gene productsand participants in DNA double-strand break repair. Carcinogenesis 31: 961-967, 2010.

16. Hu Y, Guo R, Wei J, Zhou Y, Ji W, Liu J, Zhi X and Zhang J: Effects of PI3K inhibitor NVP-BKM120 on overcoming drug resistance and eliminating cancer stem cells in human breast cancer cells. Cell Death Dis 6: e2020, 2015

17. Chou TC: Drug combination studies and their synergy quantification using the Chou-Talalay method. Cancer Res 70: 440-446, 2010.

18. Hu Y, Qiu Y, Yague E, Ji W, Liu J and Zhang J: miRNA-205 targets VEGFA and FGF2 and regulates resistance to chemotherapeutics in breast cancer. Cell Death Dis 7: e2291, 2016.

19. Modesti M and Kanaar R: DNA repair: Spot(light)s on chromatin. Curr Biol 11: R229-R232, 2001.

20. Baumann P and West SC: Role of the human RAD51 protein in homologous recombination and double-stranded-break repair. Trends Biochem Sci 23: 247-251, 1998

21. Lundin C, Schultz N, Arnaudeau C, Mohindra A, Hansen LT and Helleday T: RAD51 is involved in repair of damage associated with DNA replication in mammalian cells. J Mol Biol 328 : 521-535, 2003

22. Chang L, Graham PH, Hao J, Ni J, Bucci J, Cozzi PJ, Kearsley JH and $\mathrm{Li} \mathrm{Y:} \mathrm{PI3K/Akt/mTOR} \mathrm{pathway} \mathrm{inhibitors} \mathrm{enhance} \mathrm{radiosen-}$ sitivity in radioresistant prostate cancer cells through inducing apoptosis, reducing autophagy, suppressing NHEJ and HR repair pathways. Cell Death Dis 5: e1437, 2014.

23. Tung NM and Garber JE: BRCA1/2 testing: Therapeutic implications for breast cancer management. Br J Cancer 119: 141-152, 2018 .
24. Abramson VG, Lehmann BD, Ballinger TJ and Pietenpol JA: Subtyping of triple-negative breast cancer: Implications for therapy. Cancer 121: 8-16, 2015.

25. Huang L, Liu Q, Chen S and Shao Z: Cisplatin versus carboplatin in combination with paclitaxel as neoadjuvant regimen for triple negative breast cancer. OncoTargets Ther 10: 5739-5744, 2017.

26. Foulkes WD, Smith IE and Reis-Filho JS: Triple-negative breast cancer. N Engl J Med 363: 1938-1948, 2010.

27. Podo F, Buydens LMC, Degani H, Hilhorst R, Klipp E, Gribbestad IS, Van Huffel S, van Laarhoven HW, Luts J, Monleon D, et al; Triple-negative breast cancer: Present challenges and new perspectives. Mol Oncol 4: 209-229, 2010.

28. Lee JM, Hays JL, Annunziata CM, Noonan AM, Minasian L, Zujewski JA, Yu M, Gordon N, Ji J, Sissung TM, Figg WD, et al: Phase I/Ib Study of olaparib and carboplatin in BRCA1 or BRCA2 mutation-associated breast or ovarian cancer with biomarker analyses. J Natl Cancer Inst. 106: dju089, 2014.

29. Robertson L, Hanson H, Seal S, Warren-Perry M, Hughes D, Howell I, Turnbull C, Houlston R, Shanley S, Butler S, et al: $B R C A 1$ testing should be offered to individuals with triple-negative breast cancer diagnosed below 50 years. Br J Cancer 106: 1234-1238, 2012.

30. Juvekar A, Hu H, Yadegarynia S, Lyssiotis CA, Ullas S, Lien EC, Bellinger G, Son J, Hok RC, Seth P, et al: Phosphoinositide 3-kinase inhibitors induce DNA damage through nucleoside depletion. Proc Natl Acad Sci USA 113: E4338-E4347, 2016.

31. Lee JM, Hays JL, Chiou VL, Annunziata CM, Swisher EM, Harrell MI, Yu M, Gordon N, Sissung TM, Ji J, et al: Phase I/Ib study of olaparib and carboplatin in women with triple negative breast cancer. Oncotarget 8: 79175-79187, 2017.

32. Zhang L, Reyes A and Wang X: The Role of DNA repair in maintaining mitochondrial DNA stability. Adv Exp Med Biol 1038: 85-105, 2017.

33. Ma A and Dai X: The relationship between DNA single-stranded damage response and double-stranded damage response. Cell Cycle 17: 73-79, 2018

34. Lee JM, Ledermann JA and Kohn EC: PARP Inhibitors for BRCA1/2 mutation-associated and BRCA-like malignancies. Ann Oncol 25: 32-40, 2014

35. Farmer H, McCabe N, Lord CJ, Tutt AN, Johnson DA, Richardson TB, Santarosa M, Dillon KJ, Hickson I, Knights C, et al: Targeting the DNA repair defect in BRCA mutant cells as a therapeutic strategy. Nature 434: 917-921, 2005.

36. Bryant HE, Schultz N, Thomas HD, Parker KM, Flower D, Lopez E, Kyle S, Meuth M, Curtin NJ and Helleday T: Specific killing of BRCA2-deficient tumours with inhibitors of poly(ADP-ribose) polymerase. Nature 434: 913-917, 2005.

37. Domagala P, Huzarski T, Lubinski J, Gugala K and Domagala W: PARP-1 expression in breast cancer including BRCA1-associated, triple negative and basal-like tumors: Possible implications for PARP-1 inhibitor therapy. Breast Cancer Res Treat 127: 861-869, 2011.

38. Ossovskaya V, Koo IC, Kaldjian EP, Alvares C and Sherman BM: Upregulation of poly (ADP-ribose) polymerase-1 (PARP1) in triple-negative breast cancer and other primary human tumor types. Genes Cancer 1: 812-821, 2010.

39. Ayub A, Yip WK and Seow HF: Dual treatments targeting IGF-1R, PI3K, mTORC or MEK synergize to inhibit cell growth, induce apoptosis, and arrest cell cycle at G1 phase in MDA-MB-231 cell line. Biomed Pharmacother 75: 40-50, 2015.

40. Ibrahim YH, García-García C, Serra V, He L, Torres-Lockhart K, Prat A, Anton P, Cozar P, Guzmán M, Grueso J, et al: PI3K inhibition impairs BRCA1/2 expression and sensitizes BRCA-proficient triple-negative breast cancer to PARP inhibition. Cancer Discov 2: 1036-1047, 2012

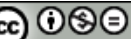

This work is licensed under a Creative Commons Attribution-NonCommercial-NoDerivatives 4.0 International (CC BY-NC-ND 4.0) License. 